\title{
PENGUJIAN STATIK DAN DINAMIK PELAT ALUMINIUM DENGAN TEKNIK INTERFEROMETRI OPTIK
}

\author{
Edi Tri Astuti ${ }^{1}$ \\ ${ }^{1}$ Universitas Pamulang, Jln. Surya Kencana No. 1, Pamulang, Tangerang Selatan 15417
}

Email: rias12@yahoo.com

Masuk : 24 Februari 2019

Direvisi :5 Maret 2019

Disetujui : 16 Maret 2019

\begin{abstract}
Abstrak: Interferometri optik telah diaplikasikan untuk menentukan deformasi suatu objek akibat pembebanan statis dan dinamis. Teknik ini memanfaatkan adanya perubahan fasa didalam gelombang cahaya koheren. Secara umum system ini terdiri dari: sistem optik, sistem perekam citra dan sistem pengolah citra. Sistem optik menentukan bentuk deformasi yang terjadi, sistem perekam citra berfungsi untuk merekam pola spekel sebelum dan sesudah terjadinya deformasi, dan sistem pengolah citra berfungsi untuk menghitung besarnya deformasi yang terjadi. Hasil dari pengamatan teknik ini adalah pola interferensi atau biasa disebut dengan pola frinji. Dengan menginterpretasikan pola-pola frinji yang didapat, maka secara kuantitatif dapat ditentukan distribusi deformasi yang terjadi.
\end{abstract}

Kata-kata kunci: Interferometri optik, deformasi, fasa, koheren, citra, pola frinji

Abstract: Optical interferometry has been applied to determine the deformation of an object due to staticand dynamic loading. This technique utilizes the phase change in coherent light waves. In general, this system consists of three systems i.e. an optical system, image recording system and image processing system. The optical system determine the shape deformation, image recording system used to record the speckle patterns before and after deformation, and the image processing system is used to calculate the amount of deformation. The result of observation this technique is interference patterns or commonly called with a fringe pattern. By interpreting fringe pattern is obtained, it can be determined quantitativelythe distribution of deformation.

Keywords: Optical interferometry, deformation, phase, coherent, image, fringe pattern

\section{PENDAHULUAN}

Penemuan laser sebagai cahaya monokhromatis dan koheren mempunyai dampak yang besar di bidang instrumentasi dan pengukuran, salah satu contohnya adalah teknik interferometri optik. Teknik ini memanfaatkan sifat koheren dari laser, sehingga diperoleh interferensi; yaitu superposisi dua gelombang. Prinsip dasar dari interferometri optik dapat dilihat pada Gambar 1.

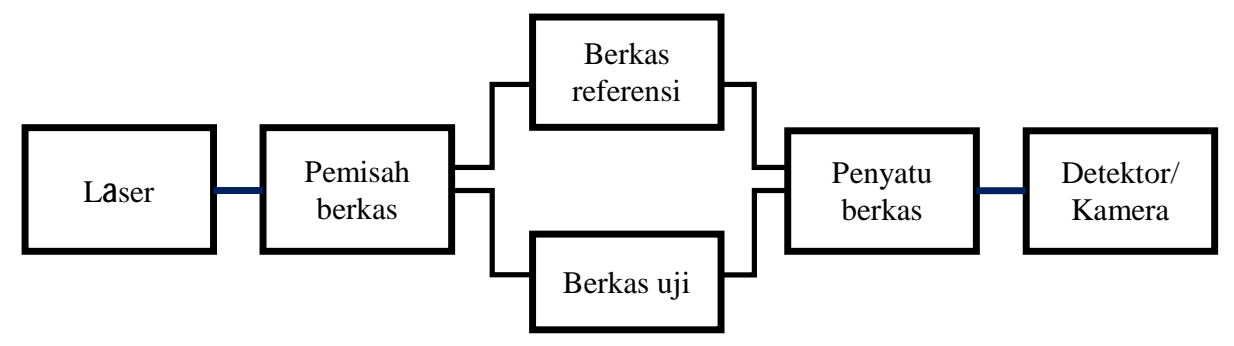

Gambar 1. Prinsip dasar interferometri. 
Teknik interferometri optik yang dibahas pada tulisan ini adalah interferometri spekel, yaitu interferometri yang memanfaatkan interferensi acak gelombang cahaya yang dihamburkan dari permukaan objek yang difus. Dari hamburan tersebut akan terlihat bintik-bintik terang gelap yang disebut dengan pola spekel (Gambar 2.a). Prinsip kerja dari teknik ini adalah dengan memberikan beban terhadap objek uji, misalnya: uji tekan, uji tarik, pemanasan, vibrasi, dan lain-lain. Apabila objek dibebani maka akan terjadi perubahan fasa dalam gelombang cahaya yang dihamburkannya. Dengan merekam citra spekel dari objek uji sebelum dan sesudah mengalami pembebanan maka akan dihasilkan pola frinji (Gambar 2.b). Dengan menginterpretasikan frinji tersebut maka beberapa sifat mekanik material dapat dianalisis.

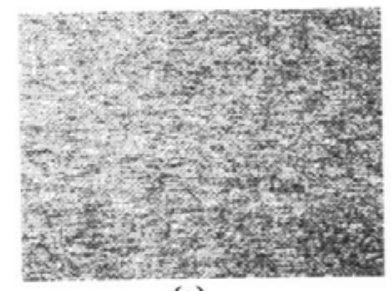

(a)



(b)

Gambar 2. (a) Pola spekel dan (b) Pola frinji

\section{METODOLOGI}

\subsection{InterferometriSpekel}

Misalkan berkas intensitas sebelum pembebanan yang diterima oleh kamera CCD adalah

$$
\text { Isebelum }=\left|\mathrm{A}_{\alpha}\right|^{2}+\left|\mathrm{A}_{\mathrm{O}}\right|^{2}+2\left|\mathrm{~A}_{\alpha} \| \mathrm{A}_{\mathrm{O}}\right| \chi 0 \sigma \phi
$$

dimana Aa adalah amplitudo gelombang acuan, Ao adalah amplitudo gelombang objek dan $\phi$ adalah fasa cahaya. Objek kemudian dibebani (misal ditarik dengan menggunakan UTM) maka akan terjadi perubahan dalam fasa gelombang cahaya. Bila perubahan fasa adalah $\Delta \phi$ maka persamaan intensitas sesudah pembebanan adalah:

$$
\text { Isesudah }=|\mathrm{A} \alpha| 2+|\mathrm{Ao}| 2+2|\mathrm{~A} \alpha \| \mathrm{Ao}| \chi \mathrm{O} \sigma(\phi+\Delta \phi)
$$

$\Delta \phi$ adalah beda fasa kedua berkas akibat adanya deformasi.

Untuk memperoleh informasi akibat adanya pembebanan terhadap objek uji maka dilakukan proses dengan cara menghitung intensitas spekel pixel per pixel.

Ada dua jenis operasi matematis yang dapat dilakukan yaitu: dengan penjumlahan dan pengurangan (subtraksi). Apabila operasi matematis penjumlahan yang dipilih maka tekniknya seperti fotografi biasa dan apabila operasi matematis pengurangan (subtraksi) yang dipilih maka tekniknya disebut dengan Electronic/Digital Speckle Pattern Interferometry (ESPI/DSPI).

Pada operasi penjumlahan, persamaannya dapat dituliskansebagai:

$$
\Sigma \mathrm{I}=2\left\{\left|\mathrm{~A}_{\alpha}\right|^{2}+\left|\mathrm{Ao}_{\mathrm{O}}\right|^{2}\right\}+4|\mathrm{~A} \alpha||\mathrm{Ao} \| \chi 0 \sigma(\phi+\Delta \phi / 2)||\chi \circ \sigma(\Delta \phi / 2)|
$$

Jika amplitudo $\mathrm{A}_{\mathrm{a}}=\mathrm{A}_{\mathrm{o}}=\mathrm{A}$, maka intensitas rata-ratanya adalah:

$$
<\Sigma \mathrm{I}>=4|\mathrm{~A}| 2\{1+<|\chi 0 \sigma(\Delta \phi / 2)|>\}
$$

Dari persamaan (4) dapat dilihat bahwa pola frinji yang terjadi dimodulasi oleh faktor $\cos (\Delta \phi / 2)$. Pola frinji akan maksimum jika $\cos (\Delta \phi / 2)=v \pi, n=0,1,2, \ldots$

Pada operasi pengurangan (subtraksi) piksel per piksel, persamaan menjadi:

$$
\Delta \mathrm{I}=4|\mathrm{~A}| 2 \sigma \iota v(\delta+\Delta \phi / 2) \sigma \iota v(\Delta \phi / 2)
$$


Intensitas rata-ratanyaadalah:

$$
<\Delta \mathrm{I}>=4<\mathrm{A} 2><|\sigma \mathrm{lv}(\Delta \phi / 2)|>
$$

Dari persamaan (6) dapat dilihat bahwa pola frinji yang terjadi dimodulasi oleh faktor sin $(\Delta \phi / 2)$. Pola frinji akan maksimum jika sin $(\Delta \phi / 2)=(2 v+1) \pi / 2, n=0,1,2, \ldots \ldots$

\subsection{ShearografiESPI}

Pada konfigurasi Shearografi ESPI, deformasi yang terjadi pada objek dipengaruhi oleh prisma tipis yang diletakkan di depan lensa (Gambar 3).



Gambar 3. Pergeseran citra akibat adanya prisma tipis

Misalkan titik A dan B pada objek terpisah pada jarak $\delta \xi$ akan mengalami deformasi pada bidang citra menjadi $\delta \xi_{\ni}$ karena adanya prisma tersebut (misal sudut prisma adalah $\alpha$ ). Persamaannya dapat dituliskan sebagai:

$$
\delta \xi_{\ni}=\Delta \mathrm{l}(v-1) \alpha
$$

dengan Diadalah jarak bidang citra terhadap lensa dan nadalah indeks bias prisma. Besarnya pergeseran pada bidang objek adalah :

$$
\delta \xi=\Delta \delta \xi_{\ni} / \mathrm{M}
$$

dan $\mathrm{M}$ adalah faktor perbesaran citra.

Dari persamaan (7) dan (8) maka persamaan pergeseran yang terjadi pada objek adalah

$$
\delta \xi=\delta \xi_{\ni}[\Delta 0 / \Delta \mathrm{l}]=\Delta \mathrm{o}(v-1) \alpha
$$

Distribusi fasa $\phi$ dalam arah $(\xi, \psi)$ dan perubahan fasa $\Delta \phi$ dalam arah (x) dalam persamaan (4) dan (6) dapat dituliskan sebagai:

$$
\begin{aligned}
& \phi(\xi, \psi)=(4 \pi / \lambda) \omega(\xi, \psi) \\
& \Delta \phi(\xi)=4 \pi / \lambda\{\delta \omega / \delta \xi) \delta \xi \square)
\end{aligned}
$$

dengan w(x,y) adalah besarnya deformasi yang terjadi.

\section{HASIL DAN PEMBAHASAN}

\subsection{Pengujian Statis}

\subsubsection{Menentukan defleksi cantilever dengan spekelfotografi}


Dari perhitungan jarak antar frinji maka deformasi di setiap titik dari objek dapat dihitung. Kontur 2-D dan 3-D untuk masing-masing deformasi diperlihatkan pada Gambar 4.



(a) $5 \mu \mathrm{m}$



(b) $10 \mu \mathrm{m}$

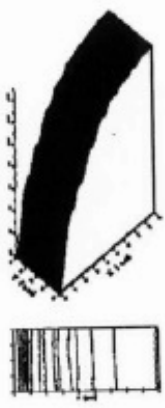

(c) $15 \mu \mathrm{m}$

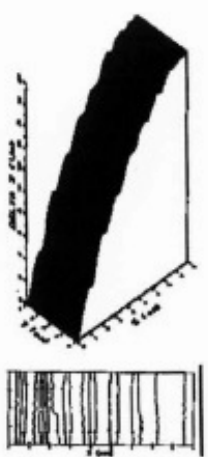

(d) $20 \mu \mathrm{m}$



(e) $25 \mu \mathrm{m}$

Gambar 4. Kontur 2-D dan 3-D dari cantilever dengan teknik spekel fotografi.

\subsubsection{Menentukan defleksi pelat aluminium dengan teknik shearografiESPI}

Tekanan mekanik dilakukan dengan menggunakan PZT dengan beban sebesar 10 volt akan memberikan pola frinji seperti terlihat pada Gambar 5 (a). Gambar 5 (b) memperlihatkan pola frinji yang terbentuk karena gerakan translasi lensa L2 sebesar 8 mm Gabungan efek dari beban PZT dan gerakan translasi lensa L2 akan memberikan pola frinji seperti diperlihatkan pada Gambar 5(c). Sedangkan distribusi fasa yang terlihat dari Gambar 5 (c) dihitung berdasarkan rumus (10) akan memberikan hasil seperti ditunjukkan pada Gambar 6.
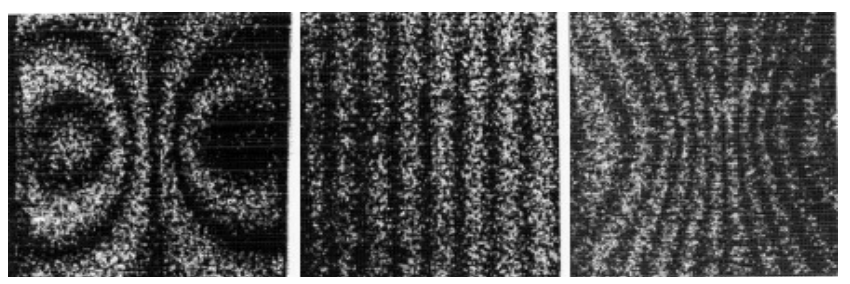

Gambar 5. Pola frinji dari (a) shearografi, (b) carrier, dan (c) shearografi dan carrier.

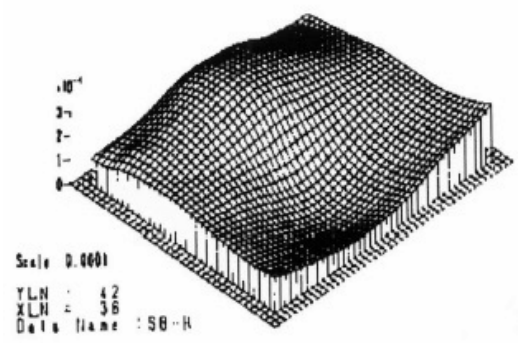

Gambar 6. Distribusi fasa yang dihitung dari Gambar 9 (c).

\subsubsection{Menentukan rotasi pelat aluminium dengan teknik ESPI berkasganda}

Hasil pola frinji yang diperoleh untuk beberapa beban rotasi diperlihatkan pada Gambar 7. Gambar 8 memperlihatkan kurva hubungan antara deformasi terhadap jumlah frinji yang terjadi. 


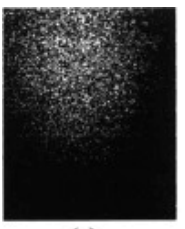

(a)

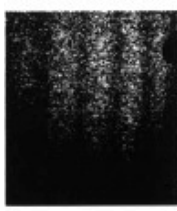

(f)

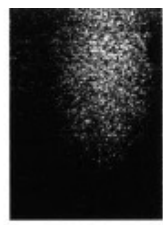

(b)

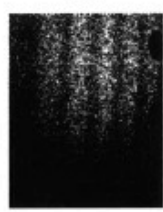

(g)

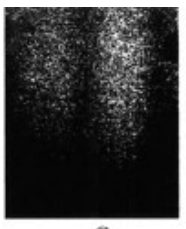

c

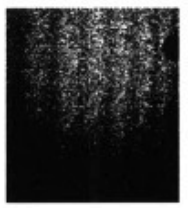

(h)



(d)

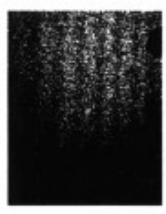

(i)

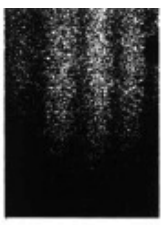

(e)

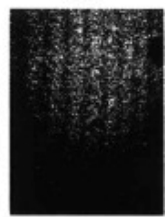

(j)

Gambar 7. Pola frinji dengan teknik ESPI untuk beberapa pengujian rotasi.



\subsection{Pengujian Dinamis}

Gambar 8. Kurva jumlah frinji terhadap deformasi pada pengujian rotasi.

Pengujian dilakukan dengan menarik objek uji menggunakan UTM dan menghasilkan kurva seperti ditunjukkan pada Gambar 9.

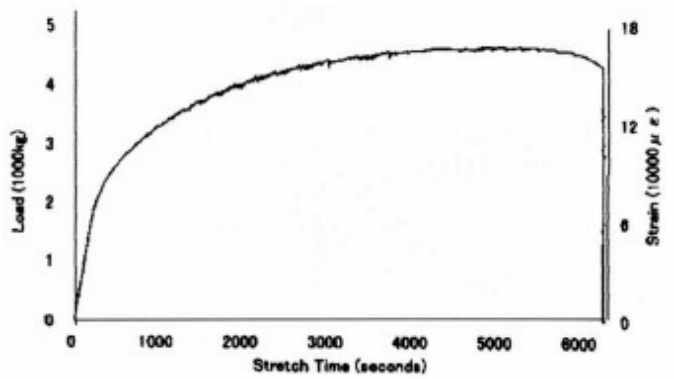

Gambar 9. Kurva strain vs waktu penarikan.

Dari kurva tersebut terlihat bahwa objek uji akan patah statis pada saat 6300 detik dihitung dari saat penarikan. Beberapa hasil substraksi dari seluruh rangkaian data citra spekel ditampilkan pada Gambar 10.

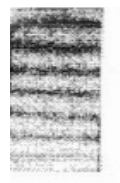

(a)

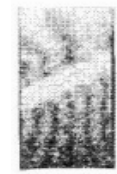

(g)



(b)

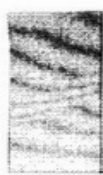

(h)

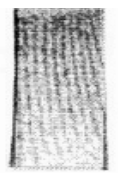

(c)

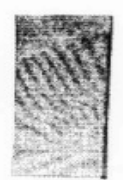

(i)

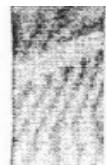

(d)

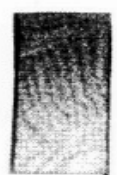

(j)

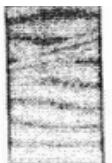

(e)

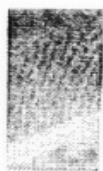

(k) (f)
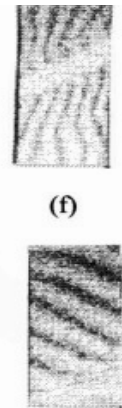

(l) 
Gambar 10. Frinji hasil uji tarik.

Gambar 10 (a) memperlihatkan objek berada di daerah elastis dan pola frinji akan mempunyai bentuk homogen. Gambar 10 (b)-(c) objek mulai memasuki daerah plastis dan terlihat adanya pita tebal yang berwarna putih, biasa disebut white band (WB). Gambar 10 (d)-(k) objek mengalami deformasi plastis, pola frinji mempunyai bentuk yang kompleks dan WB akan membuat sudut $45^{\circ}$ terhadap sumbu tegangan. Lokasi ini selalu berpindah-pindah dan akhirnya akan menetap pada satu lokasi tertentu hingga terjadinya patah statis.

\section{KESIMPULAN}

Dari data-data yang dihasilkan terlihat bahwa:

- Bentuk pola frinji tergantung dari konfigurasi optik dan beban yangdiberikan.

- Pada daerah elastis, pola frinji di seluruh permukaan objek bersifat homogen dan bersifat heterogen pada daerahplastis.

- Pada tahap deformasi plastis akan muncul WB sebagai indikator terjadinya deformasi dan lokasi ini akan berpindah-pindah selama pembebananberlangsung

- Lokasi WB akan menetap pada satu lokasi tertentu hingga terjadinya patahstatis.

\section{DAFTAR PUSTAKA}

[1] Rajpal S. Sirohi, “Speckle Methods in Experimental Mechanics”, Speckle Metrology, ed. Sirohi, Marcel Dekker, New York,1993.

[2] Edi Tri Astuti, “Interferometri Optik Dalam Pengujian Di Industri”, Lokakarya Interaktif Nasional I, JNK-Puspropen LAPAN, Februari2000.

[3] Edi Tri Astuti dan Rini Widiastuti, "Pengaruh Pemakaian Kamera Interlace dan Non- Interlace Dalam Perolehan Citra Interferometri-Spekel”, Simposium Fisika Nasional XVIII, April 2000.

[4] Edi Tri Astuti dan Suprapedi, "Pengujian Dinamik Al 2017 Dengan Menggunakan Interferometri Spekel”, Prosiding ECCIS 2000, Juni 2000 